\title{
Epidemiological study on distribution and antibiotic susceptibility patterns of Enterobacteriaceae and non-fermenting bacteria, isolated in Liguria and in a neighbouring area
}

\author{
Elisabetta Maioli', Roberto Bandettini', Rosalba Bona ${ }^{3}$, Luigi Carlo Bottaro ${ }^{4}$, \\ Roberto Capuzzo 5 , Maria Dono 6 , Pier Andrea Dusi', Maria Gabriella Mazzarello ${ }^{8}$, Silvia Reali', \\ Luisa Santoriello' ${ }^{10}$, Domizio Serra", David Usiglio' ${ }^{\prime 2}$,Anna Marchese', Eugenio A. Debbia' \\ ' Clinical Microbiology Laboratory, Section of Microbiology University of Genoa - ${ }^{2}$ Istituto Giannina Gaslini, Genoa \\ ${ }^{3}$ ASL2 San Paolo Hospital, Savona - ${ }^{4}$ ASL3 San Carlo Hospital, Genoa-Voltri - 5 "Villa Scassi" Hospital, Genoa-Sampierdarena \\ ${ }^{6}$ ASL 5 Spezzina, S. Andrea Civil Hospital, La Spezia - ${ }^{7}$ ASL I Imperiese, Ospedale di Sanremo, (IM) \\ ${ }^{8}$ ASL 22 Ovada (AL) - ${ }^{9}$ ASL4 Chiavarese, Genoa - ${ }^{10}$ Santa Corona Hospital, Pietra Ligure (SV) \\ 1 International Evangelical Hospital, Genoa - ${ }^{12}$ Ente Ospedaliero "Galliera", Genoa, Italy
}

Epidemiological study on distribution and antibiotic susceptibility patterns of Enterobacteriaceae and non-fermenting bacteria, isolated in Liguria and in a neighbouring area

Key word: Gram-negative bacteria, Epidemiology, Antibiotic-resistance, Enterobacteriaceae, Non fermenting group

\section{SUMMARY}

Introduction. An epidemiological study addressed to identify gram-negative bacteria, isolated from laboratories in a Northern area of Italy, and their antibiotic resistance patterns was conducted.

Methods. Twelve laboratories distributed on Ligurian territory or neighbouring areacollected all consecutive gram-negative isolates belonging to the Enterobacteriaceae family and non-fermenter group for 2 months and sent them to a reference laboratory.

Results. A total of 1880 pathogens were collected, including 899 and $98 \mathrm{I}$ strains isolated from nosocomial- and community-acquired infections, respectively. Escherichia coli (63.3\% of total) was the most frequently isolated pathogen followed by Pseudomonas aeruginosa (9.6\%), Proteus mirabilis (8.9\%) and Klebsiella pneumoniae (5.4\%). Nosocomial samples were collected mainly from patients in general medicine wards (19.9\%) and healthcare settings ( $14.1 \%)$. Urine was the most common clinical sample (79.9\% of the total). Other samples were sputum and bronchoaspirates (8\%), skin wounds including those from decubitus $(5.3 \%)$ and blood (4.1\%). E. coli and P. mirabilis were collected mainly from urinary tract infection while $P$. aeruginosa appears more involved in respiratory or other infections. Considering the resistance to representative classes of antibiotics, it was higher (\%) for piperacillin-tazobactam in P. mirabilis (30.3), for ceftazidime in Enterobacter aerogenes (40.8) and in Providencia stuartii (40), for imipenem and amikacin in P. aeruginosa (16.2 and I3.7 respectively), for ciprofloxacin in $P$. stuartii (66.6) and in P. mirabilis (44.7) than in others bacteria.

Conclusions. The increasing age of the population in general medical wards and healthcare settings is associated with urinary tract and bedsore infections. E. coli confirms its epidemiologic and pathogenic role, but $P$. mirabilis and $P$. aeruginosa are emerging as alternativechallenges.

Received January 9, 2008

Accepted February 26, 2008

\section{INTRODUCTION}

Since their introduction in therapy, more than fifty years ago, antibiotics have played a fundamental role for the management and control of infectious diseases (6). The development and spread of resistant bacterial strains, however, appears to modulate the actual potency of most available drugs. This phenomenon is widely distributed among a great variety of microrganisms $(1,9,20)$. Although the development of resistance is a multifactorial and unpredictable event, the selective pressure exherted by drugs remains the driving force (11). The efficacy of different antimicrobial agents also varies depen-

\section{Corresponding author: Eugenio A. Debbia}

Section of Microbiology C.A. Romanzi - DISCAT, University of Genoa - Largo Rosanna Benzi, 10 - 16132 Genoa- Italy TEL. + 39-10-3537655, 3388805256 - FAX +39-10-3537698

E-mail: eugenio.debbia@unige.it - http://www.microbiologia.unige.it/dpb/debbia.htm 
ding on time, type of microrganism, nature of the antibiotic, type of genetic mechanisms involved, etc. $(13,16,19,24,26)$. Among the several solutions suggested to fight antimicrobial resistance, appropriate and judicious use of therapeutic compounds, the development of new drugs, as well as adequate surveillance programs appear to be measures receiving a general consensus $(8,14,20)$. Surveys addressed to monitor the incidence of antimicrobial resistance in certain species as well as in different geographic areas are also needed in order to provide microbiological data for the physicians because infections are seldom diagnosed on an etiologic basis even in hospitals $(7,8,10$, 17). Therefore, the success of the empiric therapy depends, not only, on the overall conditions of the patient, but also, on the ability of the physician to guess the pathogen and its resistance pattern.

Comprehensive epidemiological studies conducted by clinical microbiologists alert the physicians about the local penetration of resistance traits thus guiding, together with pharmacological, tolerability and cost data, an appropriate selection of the most active agents $(3,5,7,10,12)$.

This survey was planned to identify the most frequent species and to evaluate their antibiotic susceptibility patterns among Gram-negative bacteria collected from clinical samples in Liguria and in a neighbouring area.

A preliminary report of this study has been presented at the XXXVI National Congress AMCLI, Rimini, 2007 (22).

\section{MATERIALS AN METHODS}

All consecutive Gram-negative bacilli, belonging to the Enterobacteriaceae family and the non-fermenting group, were collected during April-May 2007 from a total of 12 Clinical Microbiology Laboratories spread in Liguria and the neighbouring area of this region. Strains isolated from any kind of specimen, from in- and out-patients were studied, while duplicate strains from same patients were excluded. Pathogens were sent to the reference laboratory at the Section of Microbiology, DISCAT, University of Genoa together with all available data (susceptibility test results, clinical information and description of the methods used to identify strains and for the assessment of resistance to antibiotics).

Pathogens were re-identified in the reference centre and antibiotic susceptibility testing was carried out by the method suggested by CLSI (4) using the disk diffusion technique. Antibiotics for susceptibility testing were supplied by Oxoid, (Milan). A total of 1880 microrganisms causing nosocomial, healthcare settings, and communityacquired infections were collected. The complete list of the pathogens analysed and their distribution is reported in table 1. E. coli ATCC 25922, E. coli ATCC 35218, P. aeruginosa ATCC 27853, and $S$. aureus ATCC 25923, were included as quality control strains.

The enrolled Laboratories were: 1, ASL 1 Imperiese, Sanremo Hospital, Imperia; 2, ASL2 San Paolo Hospital, Savona; 3 ASL 3 San Carlo Hospital, Genoa-Voltri; 4 "Villa Scassi" Hospital, Genoa-Sampierdarena; 5, Ente Ospedaliero "Galliera Hospital, Genoa; 6 International Evangelical Hospital, Genoa; 7, Clinical Microbiology Laboratory, Section Microbiology University of Genoa; 8, Istituto Giannina Gaslini, Genoa; 9, ASL 4 Chiavarese, Genoa; 10, ASL 5 Spezzina, S. Andrea Civil Hospital, La Spezia, 11, ASL22, Ovada (Alessandria) and 12, Santa Corona Hospital, Pietra Ligure (Savona).

Among all strains tested, two type of errors, falsesusceptible (major error), and false-resistant (minor error) wereconsidered.

\section{RESULTS}

Table 1 summarises the list and the distribution of pathogens collected in this survey. A total of 1880 microorganisms were found, including 899 and 981 isolates from healthcare settings or nosocomial- and community-acquired infections, respectively. E. coli ( $63.3 \%$ of total) was by far the most frequently isolated pathogen followed by $P$. aeruginosa $(9.6 \%)$, P. mirabilis (8.9\%) and K. pneumoniae $(5.4 \%)$. The other microrganisms accounted for about $2.3 \%$ of the total. P. aeruginosa, $P$. mirabilis, Enterobacter spp, Serratia marcescens Providencia stuartii, Stenotrophomonas maltophilia and Acinetobacter baumanii were more frequently collected from healthcare settings or nosocomial samples, while the other strains were generally equally isolated from in- and outpatients, with the exception of E. coli which was found with higher incidence in the specimens from community-acquired infections (table 1).

Nosocomial samples were mainly collected from patients hospitalised in general medicine wards $(19.9 \%)$ and living in health-care settings (14.1\%) (table 2). Intensive Care Unit, General and Orthopedic Surgery (7.9 and $7.7 \%$ respectively) as well as Geriatrics $(6.7 \%)$ supplied a higher number of $P$. aeruginosa, and $P$. mirabilis strains than other clinical wards. Urine was the most common clinical sample (80\%) irrespectively of the patient location (table 3 ). In particular, urine was collected from $89.4 \%$ out- and $69.7 \%$ inpatients. Considering the pathogens isolated from this specimen, E. coli was found in 1046 out of 1189 urine, while $P$. aeruginosa, $P$. mirabilis and $K$. pneumoniae were the most frequently bacteria 
among the other pathogens isolated from urinary tract infections (table 3).

A detailed distribution of the nosocomial pathogens according to the type of clinical sample is reported in table 4 . The second most frequent submitted specimen was the indwelling catheter. Other specimens were sputum and broncho-aspirates $(8 \%)$, specimens from skin wounds including bedsore swabs (5.3\%) and blood (4.1\%). E. coli and $P$. mirabilis were isolated from urinary tract infections while $P$. aeruginosa appeared to be mainly involved in respiratory infections.

Antibiotic susceptibility patterns of strains collected from the various centres is displayed in table 5. Although resistance was present in all bacterial isolates, most of antibiotics maintained a useful activity against a large proportion of pathogens. Imipenem, in particular, was the most active compound against all species with only $2.2 \%$ of resistant isolates. Amikacin ranked second exhibiting a rate of non susceptible microrganisms no higher than $5.6 \%$ for the whole collection.

Antibiotics that showed a rate of resistance below $10 \%$ were cefepime (8.3), and cefoxitn (9.9), while ceftazidime (12.8), nitrofurantoin (13.1), ceftriaxone
(14.5), gentamicin (15.6), and augmentin (16.6) were characterised by a percentage of resistance below $20 \%$. The rate of resistance of other drugs ranged from $21.2 \%$ (piperacillin-tazobactam) to $57.0 \%$ (ampicillin).

The difference between the susceptibility patterns of the prevalent bacterial isolates, according to the site of infection, was lower in community-acquired. However, rates were often remarkably high in some cases of this group, particularly to ciprofloxacin, cefazolin, trimethoprim-sulphamethoxazole as well as ampicillin. Finally, community isolates showed about half of the resistance rate to antibiotics than nosocomial pathogens (table 5).

$P$. aeruginosa resistance rates to the most relevant antibiotics was similar or higher in nosocomial than in the community acquired isolates in comparison to that observed with the other species.

Considering the differences between antibiotic susceptibility patterns obtained by participating laboratories and those assessed by the reference centre (table 6), a general increase in the percentages of susceptibility obtained by the coordinating laboratory have been observed for all drugs with the exception of cefoxitin that showed an opposite trend.

Table I. Distribution of the strains collected in the survey according to their origin

\begin{tabular}{|c|c|c|c|c|}
\hline \multirow[b]{2}{*}{ Strain } & \multicolumn{3}{|c|}{ NUMBER AND ORIGIN } & \multirow[b]{2}{*}{$\%$} \\
\hline & Nos-HC & Com & Tot & \\
\hline Escherichia coli & 496 & 693 & 1189 & 63.3 \\
\hline Klebsiella pneumoniae & 50 & 52 & 102 & 5.4 \\
\hline Klebsiella oxytoca & 18 & 24 & 42 & 2.2 \\
\hline Enterobacter cloaceae & 27 & 17 & 44 & 2.3 \\
\hline Enterobacter aerogenes & 17 & 10 & 27 & 1.4 \\
\hline Serratia marcescens & 12 & 2 & 14 & 0.75 \\
\hline Morganella morganii & 12 & 12 & 24 & 1.3 \\
\hline Citrobacter freundii & 10 & 10 & 20 & I \\
\hline Citrobacter koseri & 5 & II & 16 & 0.85 \\
\hline Hafnia alvei & 2 & & 2 & \\
\hline Salmonella spp & I & 1 & 2 & \\
\hline Proteus mirabilis & 97 & 71 & 168 & 8.9 \\
\hline Proteus vulgaris & 3 & 2 & 5 & \\
\hline Providencia stuartii & 12 & 3 & 15 & 0.84 \\
\hline Providencia rettgeri & 1 & & 1 & \\
\hline Pseudomonas aeruginosa & 116 & 63 & 179 & 9.5 \\
\hline Pseudomonas putida & I & 1 & 2 & \\
\hline Strenotrophomonas maltophilia & 7 & 4 & 11 & 0.6 \\
\hline Acinetobacter baumanii & 6 & 1 & 7 & \\
\hline Sphingomonas paucimobilis & I & & 1 & \\
\hline Raoultella ornitholytica & 3 & 1 & 4 & \\
\hline Providencia alcalifaciens & I & & 1 & \\
\hline Achromobacter xylosoxidans & & 1 & 1 & \\
\hline Aeromonas hydrophila & I & & 1 & \\
\hline Total & 899 & 979 & 1878 & \\
\hline$\%$ & 47.9 & 52.1 & & 100 \\
\hline
\end{tabular}

Nos-HC, nosocomial-healthcare; Com, community-acquired, Tot, total 
Table 2. Distribution of nosocomial strains according to different clinical settings

\begin{tabular}{|c|c|c|c|c|c|c|c|c|c|c|}
\hline \multirow[b]{2}{*}{ Strain } & \multicolumn{10}{|c|}{ NUMBER OF STRAINS COLLECTED } \\
\hline & $\mathrm{HCS}$ & Med & Car & Pn-ID & Sur-Or & Ger & ICU & Nep & Others & Tot \\
\hline E. coli & 97 & 99 & 6 & 6 & 27 & 35 & 10 & 17 & 199 & 496 \\
\hline K. pneumoniae & 2 & 7 & & & 2 & 1 & 2 & 3 & 33 & 50 \\
\hline K. oxytoca & & 2 & & 2 & I & I & I & & II & 18 \\
\hline E. cloaceae & & 3 & 1 & & 5 & & 4 & 2 & 12 & 27 \\
\hline E. aerogenes & & 5 & & $\mathrm{I}$ & & & 2 & & 9 & 17 \\
\hline S. marcescens & & 3 & & & I & 1 & & & 7 & 12 \\
\hline M. morganii & 2 & 2 & & & 4 & & 3 & & 1 & 12 \\
\hline C freundii & & 5 & & & I & & I & & 3 & 10 \\
\hline C. koseri & & I & & & I & 1 & & 1 & I & 5 \\
\hline H. alvei & & & & & & & & & 2 & 2 \\
\hline Salmonella spp. & & & & & & & & & I & I \\
\hline P.mirabilis & 12 & 13 & & 3 & 6 & 18 & 9 & 3 & 33 & 97 \\
\hline P. vulgaris & 1 & 2 & & & & & & & & 3 \\
\hline P. stuartii & 4 & 3 & & & & 1 & I & 2 & 1 & 12 \\
\hline P. rettgeri & & & & & I & & & & & 1 \\
\hline P.aeruginosa & 6 & 28 & & 9 & 18 & 3 & 31 & 5 & 16 & 116 \\
\hline P. putida & & & & & I & & & & & I \\
\hline S. maltophilia & & 2 & & 1 & & & 3 & & 1 & 7 \\
\hline A. baumanii & & I & & & I & & 4 & & & 6 \\
\hline S. paucimobilis & & & & I & & & & & & I \\
\hline R. ornitholytica & 1 & 2 & & & & & & & & 3 \\
\hline P. alcalifaciens & & I & & & & & & & & 1 \\
\hline A. xylosoxidans & & & & & & & & & & \\
\hline A. hydrophila & I & & & & & & & & & I \\
\hline Total & 126 & 179 & 7 & 23 & 69 & 61 & 71 & 33 & 330 & 899 \\
\hline
\end{tabular}

HCS, Healthcare setting, Med, Medicine; Car, Cardiology; Pn-ID, Pneumology-Infectious Diseases Sur-Or,

General Surgery- Orthopedics, Ger, Geriatrics; ICU, Intensive Care Unit; Nep, Nephrology.

Table 3. Distribution of the strains collected from urine and other clinical samples

\begin{tabular}{|c|c|c|c|c|c|c|c|c|c|}
\hline \multirow[b]{3}{*}{ Strain } & \multicolumn{9}{|c|}{ ORIGIN OF THE STRAINS AND THEIR NUMBER } \\
\hline & \multicolumn{3}{|c|}{ COMMUNITY-ACQUIRED } & \multicolumn{3}{|c|}{ NOSOCOMIAL } & \multicolumn{3}{|c|}{ TOTAL } \\
\hline & Urine & Others & Total & Urine & Others & Total & Urine & Others & Total \\
\hline E. coli & 660 & 33 & 693 & 386 & 110 & 496 & 1046 & 143 & 1189 \\
\hline K.pneumoniae & 45 & 7 & 52 & 38 & 12 & 50 & 83 & 19 & 102 \\
\hline K. oxytoca & 20 & 4 & 24 & 13 & 5 & 18 & 33 & 9 & 42 \\
\hline E. cloaceae & II & 6 & 17 & 19 & 8 & 27 & 30 & 14 & 44 \\
\hline E. aerogenes & 8 & 2 & 10 & 8 & 9 & 17 & 16 & 11 & 27 \\
\hline S. marcescens & & 2 & 2 & 7 & 5 & 12 & 7 & 7 & 14 \\
\hline M. morganii & 10 & 2 & 12 & 7 & 5 & 12 & 17 & 7 & 24 \\
\hline C. freundii & 7 & 3 & 10 & 10 & & 10 & 17 & 3 & 20 \\
\hline C. koseri & 11 & & 11 & 5 & & 5 & 16 & & 16 \\
\hline Hafnia halvei & & & & 1 & 1 & 2 & I & 1 & 2 \\
\hline Salmonella & & 1 & 1 & & 1 & 1 & & 2 & 2 \\
\hline P.mirabilis & 63 & 8 & 71 & 84 & 13 & 97 & 147 & 21 & 168 \\
\hline$P$ vulgaris & & 2 & 2 & 1 & 2 & 3 & I & 4 & 5 \\
\hline P.stuartii & 3 & & 3 & 12 & & 12 & 15 & & 15 \\
\hline P. rettgeri & & & & & 1 & I & & 1 & I \\
\hline P.aeruginosa & 31 & 32 & 63 & 33 & 83 & 116 & 64 & 115 & 179 \\
\hline P. putida & 1 & & 1 & & 1 & 1 & 1 & 1 & 2 \\
\hline S. maltophilia & 3 & 1 & 4 & & 7 & 7 & 3 & 8 & 11 \\
\hline A. baumanii & & I & 1 & & 6 & 6 & & 7 & 7 \\
\hline S. paucimobilis & & & & & 1 & 1 & & 1 & 1 \\
\hline R. ornitholytica & I & & 1 & 2 & 1 & 3 & 3 & 1 & 4 \\
\hline P. alcalifaciens & & & & 1 & & 1 & 1 & & 1 \\
\hline A. xylosoxidans & I & & I & & & & I & & 1 \\
\hline A. hydrophila & & & & & 1 & 1 & & 1 & 1 \\
\hline Total & 875 & 104 & 979 & 627 & 272 & 899 & 1502 & 376 & 1878 \\
\hline
\end{tabular}


Table 4. Distribution of nosocomial strains according to the type of clinical samples

\begin{tabular}{|c|c|c|c|c|c|c|c|c|c|}
\hline \multirow[b]{2}{*}{ Strain } & \multicolumn{8}{|c|}{ NUMBER AND TYPE OF CLINICAL SAMPLE } & \multirow[b]{2}{*}{ Total } \\
\hline & Uri & IndC & $\mathrm{Sp}-\mathrm{Ba}$ & Blood & WbSw & OthSw & VagSw & Others & \\
\hline E. coli & 306 & 78 & 16 & 25 & 21 & 9 & 23 & 18 & 496 \\
\hline K.pneumoniae & 34 & 4 & 4 & 4 & 2 & & I & 1 & 50 \\
\hline K. oxytoca & 12 & 1 & 3 & 1 & & & & $\mathrm{I}$ & 18 \\
\hline E. cloaceae & 17 & 2 & & & 2 & 2 & & 4 & 27 \\
\hline E. aerogenes & 4 & 4 & 5 & & 2 & & 2 & & 17 \\
\hline S. marcescens & 5 & 2 & 3 & 1 & 1 & & & & 12 \\
\hline M. morganii & 9 & & 2 & & I & & & & 12 \\
\hline C. freundii & 10 & & & & & & & & 10 \\
\hline C. koseri & 5 & & & & & & & & 5 \\
\hline H. alvei & 1 & & & & & & 1 & & 2 \\
\hline Salmonella spp. & & & & & & & & 1 & 1 \\
\hline P. mirabilis & 68 & 16 & 2 & & 2 & 2 & 2 & 5 & 97 \\
\hline P. vulgaris & I & & 1 & & 1 & & & & 3 \\
\hline P. stuartii & 12 & & & & & & & & 12 \\
\hline P. rettgeri & & & & & I & & & & 1 \\
\hline P. aeruginosa & 26 & 7 & 28 & 3 & 20 & 12 & I & 19 & 116 \\
\hline P. putida & & & & & & & & & 1 \\
\hline S. maltophilia & & & 5 & I & & & & 1 & 7 \\
\hline A. baumanii & & 1 & I & 2 & & & & 2 & 6 \\
\hline S. paucimobilis & & & 1 & & & & & & I \\
\hline R. ornitholytica & 1 & 1 & I & & & & & & 3 \\
\hline P. alcaliafciens & & & & & & & & 1 & $\mathrm{I}$ \\
\hline A. xylosoxidans & & & & & & & & & 0 \\
\hline A. hydrophila & & & & & & & & 1 & I \\
\hline Total & 512 & 116 & 72 & 37 & 53 & 25 & 30 & 54 & 899 \\
\hline
\end{tabular}

Uri, urine; IndC, Indwelling catheter; Sp-Ba, sputum-broncho-aspirate; WbSw, Bedsore swab; OthSw, other swab; vagSw, vaginal swab.

\section{DISCUSSION}

The need for local, national and international surveillance to evaluate the rate of bacterial resistance to antibiotics, is generally suggested in order to chose the best drug for empiric therapy, and gain information about the emerging pathogens and the evolution of antibiotic resistance to the most frequently used antimicrobials $(7-10,14,20)$.

This study describes most prevalent agents of bacterial infections in Liguria and their antibiotic susceptibility patterns, evaluating samples from 1880 patients recruited by 12 hospitals distributed throughout Liguria. Antibiotic susceptibility of all isolates determined in hospital laboratories was re-determined using a standard quality procedure based on the disk diffusion test. Bacterial isolates were examined for their susceptibility pattern to most commonly used antibiotic classes.

As expected, urinary tract infections accounted for more than $90 \%$ of all infections with three species (E. coli, P. aeruginosa and P. mirabilis accounting for $81.8 \%$ of all the isolates. Although comparisons are not feasible due to differences among studies, the distribution of the type of infections and causative agents appears to be in line with previous investigations conducted in Italy (18).

$P$. aeruginosa was the most more frequent pathogen lsolated from ICU patients, accounting for $43.6 \%$ of all isolates collected in these wards. Interestingly, Acinetobacter represented only $5.6 \%$ of the ICU isolates, with 4 out of 7 isolated strains from ICU, outlining the increasing importance of, Acinetobac among infections in this setting $(2,25)$.

This study shows that species with intrinsic or acquired antibiotic resistance are not widespread in hospitals and healthcare settings of this area of Italy. Although extended-spectrum $\beta$-lactamase production was not directly tested, resistance to third generation cephalosporins was rarely observed in Gram-negative isolates. For instance, $7.6 \%$ of E. coli and $2.9 \%$ of $K$. pneumoniae isolates were not inhibited by ceftazidime; these values decreased to 4.8 and 2.0 respectively when tested in the reference centre. A similar behaviour was shown by Enterobacter spp, and M. morganii whose level of resistance to ceftazidime was strongly reduced after a revaluation, while resistance to fluoroquinolones remained high (about $20 \%$ ) after the confirmation procedure. Re-testing antibiotic susceptibility in the reference centre showed that the great majority of the total isolates were fully susceptible to imipenem and amikacin ( 2.1 and $1.8 \%$ of resistant rate, respectively) and only gentamicin and ciprofloxacin exhibited a resistance rate of 13.3 and $20.7 \%$ respectively, 
Table 5. Incidence of resistance (\%) to selected antibiotics in 1878 strains

\begin{tabular}{|c|c|c|c|c|c|c|c|c|c|c|c|c|c|c|c|}
\hline All-strains & Number & amp & aug & tzp & $\mathrm{cfz}$ & caz & cro & fep & fox & imi & ak & gen & cip & sxt & nit \\
\hline E. coli & 1189 & 52.7 & 14.1 & 9 & 26.9 & 7.6 & 11 & 6.6 & 6 & 0.2 & 1.3 & 10.2 & 25.3 & 28.6 & 9.4 \\
\hline K.pneumoniae & 102 & na & 18.6 & 13.7 & 5.9 & 2.9 & 5.9 & 2.9 & 0 & 0 & 0.9 & 1.9 & 5.8 & 3.9 & 36.3 \\
\hline K. oxytoca & 42 & 95.2 & 14.3 & 21.4 & 16.7 & 4.8 & 2.4 & 2.4 & 2.4 & 0 & 2.4 & 2.4 & 7.1 & 9.5 & 14.3 \\
\hline E. cloaceae & 44 & na & na & 27.3 & na & 36.4 & 36.4 & 7.3 & na & 0 & 4.5 & 22.3 & 20.4 & 18.2 & 27.3 \\
\hline E aerogenes & 27 & na & na & 33.4 & na & 40.8 & 48.1 & 13 & na & 0 & 14.8 & 11.1 & 18.5 & 26 & 48.1 \\
\hline S marcescens & 14 & na & na & 28.6 & na & 0 & 57.1 & 0 & 0 & 0 & 7.1 & 7.1 & 28.6 & 35.7 & 64.3 \\
\hline M. morganii & 24 & na & na & 12.5 & na & 35.7 & 33.3 & 0 & 12.5 & 4.1 & 8.3 & 8.3 & 25 & 33.3 & na \\
\hline$C$ freundii & 20 & na & na & 45 & na & 45 & 50 & 25 & na & 0 & 25 & 28 & 30 & 15 & 20 \\
\hline C. koseri & 16 & na & 6.2 & 6.2 & 0 & 0 & 0 & 0 & 0 & 0 & 0 & 0 & 0 & 0 & 12.5 \\
\hline P.mirabilis & 168 & 77.4 & 31.5 & 30.3 & 34 & 22 & 26.8 & 10.7 & 9.5 & 3.6 & 7.1 & 41 & 44.7 & 48.2 & na \\
\hline P.stuartii & 15 & na & na & 20 & na & 40 & 66.7 & 33.3 & 6.6 & 6.6 & 0 & 86.7 & 66.6 & 86.7 & na \\
\hline P.aeruginosa & 179 & na & na & 37.4 & na & 29.4 & na & 26.2 & na & 16.2 & 28 & 29.6 & 38 & na & na \\
\hline S. maltophilia & 11 & na & na & nt & na & 27.2 & na & 27.2 & na & na & 54.5 & 54.5 & 45.4 & 36.4 & na \\
\hline Others & 27 & 57.7 & 46.1 & 19.2 & 27 & 19.2 & 23 & 19.2 & 19.2 & 7.7 & 15.4 & 23 & 30.8 & 42.3 & 19.2 \\
\hline Total & 1878 & 57.0 & 16.6 & 21.2 & 25.9 & 12.8 & 14.9 & 8.3 & 9.9 & 2.2 & 5.6 & 15.6 & 26.6 & 28.0 & 13.1 \\
\hline Com-acq & Number & amp & aug & tzp & $\mathrm{cfz}$ & caz & cro & fep & fox & imi & ak & gen & cip & sxt & nit \\
\hline E. coli & 693 & 48.9 & 12.5 & 6.1 & 24.5 & 5.2 & 6.4 & 4.6 & 6.2 & 0 & 0.7 & 9.4 & 22.6 & 28 & 7.3 \\
\hline K.pneumoniae & 52 & na & 3.8 & 3.8 & 1.9 & 0 & 0 & 1.9 & 0 & 0 & 0 & 0 & 7.7 & 3.8 & 42.3 \\
\hline K. oxytoca & 24 & 91.6 & 8.3 & 8.3 & 20.8 & 0 & 0 & 0 & 0 & 0 & 0 & 0 & 0 & 4.1 & 12.5 \\
\hline E. cloaceae & 17 & na & na & 29.4 & na & 35.3 & 35.3 & 0 & na & 0 & 11.8 & 29.4 & 29.4 & 11.8 & 35.3 \\
\hline$E$ aerogenes & 10 & na & na & 40 & na & 30 & 80 & 20 & na & 0 & 20 & 50 & 30 & 30 & 0 \\
\hline M. morganii & 12 & na & na & 8.3 & na & 33.3 & 8.3 & 0 & 41.6 & 8.3 & 16.6 & 8.3 & 33.3 & 33.3 & na \\
\hline$C$ freundii & 10 & na & na & 40 & na & 30 & 80 & 20 & na & 0 & 20 & 50 & 30 & 30 & 0 \\
\hline C. koseri & 11 & na & 9 & 9 & 0 & 0 & 0 & 0 & 0 & 0 & 0 & 0 & 0 & 0 & 18.2 \\
\hline P.mirabilis & 71 & 46.5 & 5.6 & 9.8 & 21.1 & 8.4 & 14 & 7 & 5.6 & 2.8 & 1.4 & 24 & 30.1 & 36.6 & na \\
\hline P.aeruginosa & 63 & na & na & 79 & na & 28.5 & na & 28.5 & na & 17.5 & 34.9 & 30.2 & 33.3 & na & na \\
\hline Total & 963 & 50 & 9.9 & 12.0 & 22.4 & 7.8 & 8.1 & 5.3 & 6.0 & 1.4 & 3.5 & 11.7 & 22.4 & 25.4 & 10.9 \\
\hline Nosocomial & Number & amp & aug & tzp & $\mathrm{cfz}$ & caz & cro & fep & fox & imi & ak & gen & cip & sxt & nit \\
\hline E. coli & 496 & 58 & 16.7 & 13.7 & 30.2 & 11 & 17.4 & 9.2 & 5.9 & 0.6 & 2.2 & 11.2 & 28.9 & 29.3 & 12.4 \\
\hline K.pneumoniae & 50 & na & 36 & 24 & 10 & 6 & 12 & 4 & 0 & 0 & 2 & 4 & 4 & 4 & 30 \\
\hline K. oxytoca & 18 & 100 & 27.7 & 27.7 & 11.1 & 11.1 & 22.2 & 5.5 & 5.5 & 0 & 5.5 & 5.5 & 16.6 & 16.6 & 16.6 \\
\hline E. cloaceae & 27 & na & na & 25.9 & na & 37 & 40.7 & 11.1 & na & 0 & 22.2 & 18.5 & 14.8 & 22.2 & 22.2 \\
\hline$E$ aerogenes & 16 & na & na & 56.2 & na & 56.2 & 56.2 & 18.7 & na & 18.7 & 25 & 12.5 & 31.2 & 43.7 & 37.5 \\
\hline S marcescens & 12 & na & na & 33.3 & na & 0 & 58.3 & 0 & 0 & 0 & 8.3 & 8.3 & 33.3 & 41.6 & 75 \\
\hline M. morganii & 12 & na & na & 16.6 & na & 8.3 & 58.3 & 25 & 16.6 & 0 & 0 & 8.3 & 16.6 & 33.3 & 58.3 \\
\hline C freundii & 10 & na & na & 50 & na & 60 & 100 & 30 & na & 0 & 30 & 20 & 30 & 0 & na \\
\hline P.mirabilis & 97 & 100 & 50.5 & 45.4 & 43.3 & 32 & 36 & 15.8 & 12.4 & 4.1 & 11.3 & 53.6 & 51.5 & 56.7 & na \\
\hline P.stuartii & 14 & na & 42.8 & 14.3 & na & 35.7 & 50 & 14.3 & 0 & 7.1 & 0 & 71.4 & 50 & 71.4 & na \\
\hline P.aeruginosa & 116 & na & na & 14.6 & na & 29.8 & na & 24.8 & na & 15.5 & 24.1 & 29.3 & 40.05 & na & na \\
\hline Total & 868 & 66.0 & 20.7 & 19.6 & 30.1 & 18.0 & 22.7 & 10.8 & 6.1 & 3.3 & 7.6 & 19.0 & 31.2 & 30.1 & 16.0 \\
\hline
\end{tabular}

Amp, ampicillin; aug, amoxicillin-clavulanate; tzp, piperacillin-tazobactam; cfz, cefazolin; caz, ceftazidime;cro, ceftriaxone; fep, cefepime; fox, cefoxitin; imi, imipenem; ak, amikacin; gen, gentamicin; cip, ciprofloxacin; sxt, trimethoprim-sulphamethoxazole; nit, nitrofurantoin. na, not assessed.

Others: H. alvei (2), Salmonella spp (2), P. vulgaris (5), P. rettgeri (I), P. putida (2); A. baumanii (7), S. paucimobilis (I), R. ornitholytica (4), P. alcalifaciens (I), A. xylosoxidans (I), A. hydrophila (I).

Com-acq, community-acquired. Data concerning species with less than ten isolates are not reported

being these values significantly lower than those reported in a recent national survey on bacteria isolated from severe infections (18). Multidrugresistant strains of $P$. aeruginosa, i.e. pathogens resistant simultaneously to gentamicin, ceftazidime, and ciprofloxacin, have been found in healthcare or nosocomial as well as in community-acquired infections.

Finally, the $7 \mathrm{~A}$. baumanii isolates in this study showed a high level of resistance to the great majority of the antibiotics (only 1 strain was resistant to just imipenem and amikacin. Clusters of multidrug-resistant $A$. baumanii infections have become a rather frequent event in ICUs, as witnessed in very recent reports from Italian investigators $(2,18,25)$.

Differences in the antibiotic susceptibility patterns observed between the reference centre and the participating laboratories can be attributed to the different methodologies adopted, as well as the lack of information about the periodical inclusion of quality control strains in the usual protocol.

The increasing age of the population of this area of Italy leads to an increase of patients assisted in the healthcare settings that is similar to a nosocomial environment, where a high number of urinary tract or bedsore infections are present.

The present findings do not give information about genetic determinants of antibiotic resistance and clonal relatedness of resistant isolates. Studies to expand these important points are underway.

This is the first epidemiologic study in Liguria and neighbouring area and results presented here 
are of high interest for comparative epidemiologic analysis suggesting indications for the empirical therapy at a local level.

\section{ACKNOWLEDGEMENTS}

The authors would like to thank Guendalina Vito, Eliana Regola, Daniele Croxatto, Gabriele Fasce, and Enrico Varlese, who helped at various stages of this project

\section{REFERENCES}

1. Alkshun MN, Levy SB. Molecular mechanism of antibacterial multidrug resistance. Cell 2007; 128: 1037-50.

2. Bonomo RA, Szabo D. Mechanisms of multidrug resistance in Acinetobacter species and Pseudomonas aeruginosa. Clin Infect Dis 2006; 43 (Supp12) S49-S56.

3. Clark N M, Patterson, J, Lynch JP. Antimicrobial resistance among Gram-negative organisms in the intensive care unit. Curr Op Crit Care 2003, 9: 413-23.

4. Clinical and Laboratory Standards Institute. Performance Standard for Antimicrobial Susceptibility Tests; Seventeenth Informational Supplement. CLSI document M100-S17, 2007.Wayne, PA.

5. Cockerill FR, Smith TF. Response of the Clinical Microbiology laboratory to emerging (new) and reemerging infectious diseases. J Clin Microbiol 2004, 42: 2359-65.

6. Davies J. Microbes have the last word. EMBO Reports 2007; 8: 616-21.

7. Felmingham D. The need for antimicrobial resistance surveillance. J Antimicrob Chemother 2002; 50, (suppl): 1-7.

8. Gastmeier P. Nosocomial infection surveillance and control policies. Curr Opin Infect Dis 2004, 17: 295-301.

9. Howard DH, Scott RD, Packard R, Jones DA. The global impact of drug resistance. Clinical Infectious Diseases 2003; 36 (Suppl 1): S4-10.

10. Jones RN, Masterson R. Determining the value of antimicrobial surveillance programs. Diagn Microbiol Infect Dis 2001; 41: 171-5.

11. Livermore DM. Bacterial resistance: origins, epidemiology, and impact. Clin Infect Dis 2003; 36 (Suppl 1): S11-23.

12. Livermore DM. The zeitgeist of resistance. J Antimicrob Chemother 2007; 60 (Suppl 1) i59-i61.

13. Livermore DM, Pearson A. Antibiotic resistance: location, location, location. Clin Microbiol Infect 2007; 13 (Suppl 2): $7-16$

14. Magee JT, Heginbothom ML, Mason BW. Finding a strategy: the case for co-operative research on resistance epidemiology. J Antimicrob Chemother 2005; 55: 628-33.

15. McGowan JE, Tenover FC. Confronting bacterial resistance in healthcare settings: a crucial role for microbiologists. Nat Rev Microbiol 2004; 2: 251-8.
16. Morens DM, Folkers GK, Fauci AS. The challenge of emerging and re-emerging infectious disease. 2004, Nature vol. 430 .

17. Nicolau D. Clinical and economic implications of antimicrobial resistance for the management of communityacquired respiratory tract infections. J Antimicrob Chemother 2002; 50 (Suppl S1): 61-70.

18. Nicoletti G, Schito GC, Fadda G, et al, for the GIGAR, (Gruppo Cooperativo, Infezioni Gravi ed Antibiotico Resistenza). Bacterial isolates from severe infections and their Antibiotic susceptibility patterns in Italy: a nationwide study in the hospital settings. J Chemother 2006; 18 : 589-602.

19. O'Brien TF. Emergence, spread and environmental effect of antimicrobial resistance: how use of an antimicrobial anywhere can increase resistance to any antimicrobial anywhere else. Clin Infect Dis 2002; 34 (Suppl 3): s78-84.

20. Peterson LR. Squeezing the antibiotic balloon: the impact of antimicrobial classe on emerging resistance. Clin Microbiol Infect 2005; 11 (Suppl 5): 4-16.

21. Raoult D, Fournier PE, Drancourt M. What does the future hold for clinical microbiology. Nat Rev Microbiol 2004, 2 : 151-9.

22. Regola E, Vito G, Andreotti M, et al. Epidemiologia di Enterobacteriaceae e non fermentanti, isolati nell'area ligure. XXXVI Congr Naz AMCLI 2007; Abst 162, 269 Rimini.

23. Sanders CC, Peyret M, Moland ES, et al. Ability of the Vitek 2 advanced expert system to identify $\beta$-lactam phenotypes in isolates of Enterobacteriaceae and Pseudomonas aeruginosa. Journal of Clinical Microbiology 2000; 38: 570-4.

24. Tenover FC. Development and spread of bacterial resistance to antimicrobial agents: an overview. Clin Infect Dis 2001; 33 (Suppl 3): S108-S15.

25. Urban C, Segal-Maurer S, Rallal J. Considerations in control and treatment of nosocomial infections due to multidrug-resistant Acinetobacter baumanii Clin lnfect Dis 2003; 36: 1268-74.

26. Wood MJ, Moellering RC. Microbial resistance: bacteria and more. Clin Infect Dis 2003; 36 (Suppl 1): S2-3. 